\title{
Vacuum technology in the extraction of cannabinoids
} https://doi.org/10.51167/ice00002

\author{
Sammy Rabuchin \\ Busch Vacuum Israel Ltd, 1 Mevo Sivan Street, P.O Box 8428, Qiryat Gat 8202271, Israel \\ Email: Sammy.Rabuchin@busch.co.il
}

\section{Introduction}

The use of the cannabis plant for the manufacturing of medicines is increasing enormously after its release as a remedy in many countries. Cannabinoids are of particular importance for medical applications. The primary active substances, cannabidiol (CBD) and tetrahydrocannabinol (THC), are mainly in demand from a medical perspective. Vacuum technology plays an important role in the industrial processing of cannabis to obtain high quality CBD and THC. It can be used for drying, extraction, evaporation and distillation. Vacuum technology alone enables the effective and efficient manufacturing of these pure active ingredients from the components of the cannabis plant.

Cannabis plants contain a variety of cannabinoids, terpenes, flavonoids and other substances. The psychoactive cannabinoid THC can be used for the treatment of allergies, pain therapy, anxiety and eating disorders and also in cancer therapy. The cannabinoid CBD promotes nervous system response and is analgesic and anti-inflammatory. CBD is also used in food and cosmetics. In addition to these two active ingredients, other products can be obtained from the hemp plant, such as saturated fatty acids, beta-carotene, omega-3 fatty acids and vitamin $\mathrm{E}$.

The extraction of the active ingredients THC and CBD involves various processes (Figure 1). Some of them run under vacuum in order to enable the most effective and efficient manufacturing of these active ingredients. The various processes are described below.

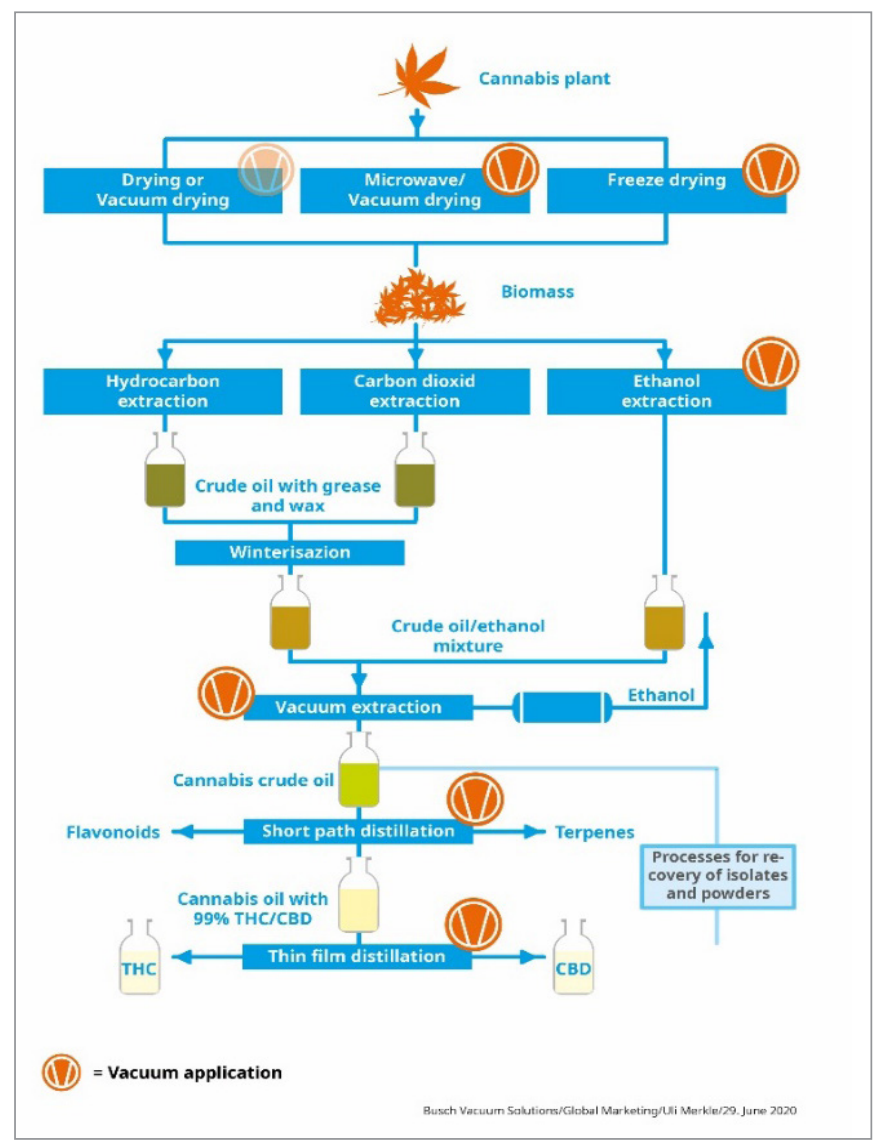

Figure 1. The process steps for obtaining CBD and THC. Source oBusch Vacuum Solutions

Sammy Rabuchin was born in Copenhagen, Denmark and has lived in Kfar Saba since 1983. He is married with three children. He received his BSc in Mechanical Engineering from Ben-Gurion University of the Negev. He worked as a mechanical engineer at the Standards Institute of Israel and was then production and operation manager at Oxygen and Argon Works Ltd. He has fifteen years of experience as a vacuum sales and marketing engineer, previously at a vacuum representative company and currently at Busch Vacuum Israel Ltd.

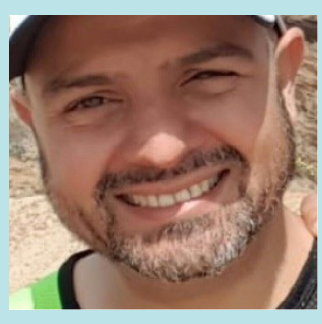




\section{Freeze drying}

Freeze drying has become prevalent in the industrial drying of harvested cannabis plants. It enables fast, yet gentle drying of plants or plant parts that consist of $80 \%$ water. Freeze drying is based on the physical process of sublimation: Water passes under vacuum directly from a solid, frozen state to a gaseous state - the ice evaporates. The cannabis plants or their components are first deep-frozen at normal pressure. They are then subjected to a vacuum in which frozen water sublimates from the product, thus becoming gaseous. This allows the water to be suctioned off as vapor without heating it. This means that the substances are not negatively affected either by excessively high temperatures or by a long drying period. The correct use of vacuum technology is important for this drying process. Normally, depending on the plant, absolute pressures of 0.001 to 0.5 millibar are used for freeze drying.

Another drying method is microwave-assisted drying. This procedure is faster than freeze drying. The pressure level lies in the range 10 to 400 mbar.

\section{Extraction}

During extraction, cannabis oil is obtained from the dried plant parts - the so-called biomass. Cannabis oil is an extract from the cannabis plant that, unprocessed, contains a variety of cannabinoids. The most desired ones are CBD and THC, which account for between 60 and 80 percent. Furthermore, cannabis oil contains essential oils (terpenes), flavonoids, lipids, waxes and grease. The composition of this raw oil depends on the plant itself or on the components used, the extraction method chosen and parameters such as temperature, pressure conditions and extraction time.

Hydrocarbon and carbon dioxide extraction were initially the most common methods of extracting oil from the cannabis plant. Both extraction processes require subsequent winterization in which the crude oil is mixed with ethanol, cooled to $-40^{\circ} \mathrm{C}$ and subjected to cold filtration. This removes waxes and grease from the oil.

\section{Ethanol extraction}

Ethanol extraction has become established in the industrial processing of the cannabis plant. This procedure combines the high efficiency of hydrocarbon extraction with the high level of safety of carbon-dioxide extraction. There is also no need for winterization. Since ethanol is a very effective solvent that also extracts undesirable substances from the biomass, extraction is carried out with supercooled (cryogenic) ethanol under vacuum at absolute pressures of 0.001 to $1 \mathrm{mbar}$ (Figure 2). The desired extraction properties are thus achieved. The intermediate product of the extraction is always a mixture of cannabis oil and ethanol.

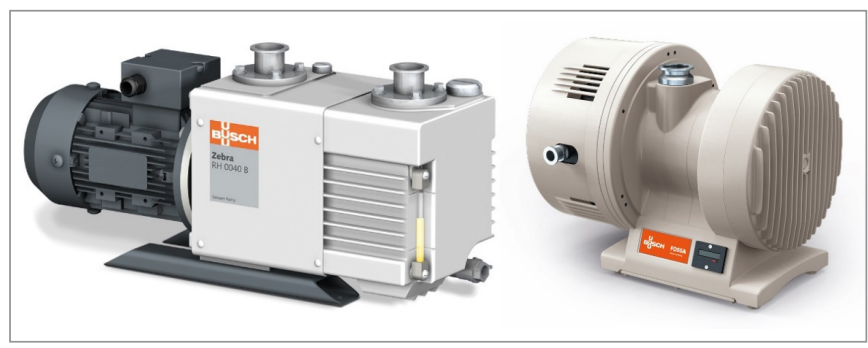

Figure 2. Two-stage rotary-vane vacuum pumps and scroll vacuum pumps often used for freeze drying, ethanol extraction, short-path and thin-film distillation in laboratories and for processing smaller quantities. Source $\odot$ Busch Vacuum Solutions

\section{Vacuum evaporation}

The cannabis oil/ethanol mixture is then fed into an evaporation process to remove the ethanol it contains. Due to ethanol's low boiling point, this can be done in lab or pilotscale processes in a rotary evaporator at room temperature or with modest heat addition and a vacuum of 50 to 100 mbar. Liquid-ring vacuum pumps with ethanol as operating fluid can be used for this. The ethanol can be re-liquefied via a condenser and fed into the cycle.

For industrial-scale operation, thin or wipe film evaporators can be used to efficiently remove the bulk of the solvent producing the crude oil, working at a higher vacuum level. After vacuum evaporation, crude oil with a THC/CBD concentration of 60 to 80 percent is obtained.

\section{Distillation}

As well as cannabinoids, the cannabis crude oil contains terpenes as aromatic oils and flavonoids as bioactive flavor carriers. They need to be separated in a distillation process. One of the most commonly used and most efficient distillation processes is the so-called short-path distillation. This involves taking the different boiling points of the individual components of the oil under certain temperatures and pressures into account for the separation. While THC begins to evaporate at an atmospheric pressure of $157^{\circ} \mathrm{C}, \mathrm{CBD}$ evaporates at 160 to $180^{\circ} \mathrm{C}$. Individual terpenes and flavonoids have lower boiling points. Carrying out the distillation under 
vacuum allows for a reduction in the temperatures required to boil the various cannabinoids. Short-path distillation works at a vacuum level of 0.001 to $1 \mathrm{mbar}$ (Figure 3). The oil is slowly heated and the vacuum level adjusted so that terpenes and flavonoids evaporate selectively and can be obtained by condensation. What remains as concentrate is a liquid containing the cannabinoids THC and CBD in $99 \%$ purity.

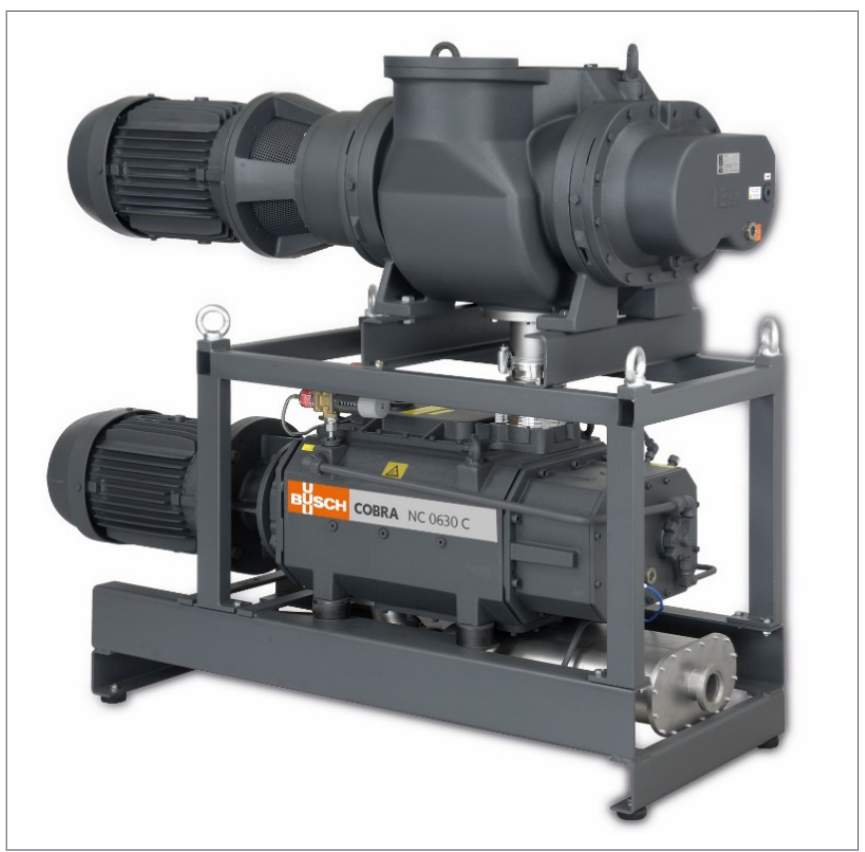

Figure 3. Vacuum systems with screw vacuum pumps and vacuum boosters ideally suited to many industrial cannabinoid extraction processes. Source @Busch Vacuum Solutions
In a second distillation step, the THC is separated from the CBD in a thin-film evaporator. Thin-film evaporators operate similarly to short-path distillators under vacuum and different temperatures. In principle, distillation is carried out at vacuum levels of around $1 \mathrm{mbar}$ and higher temperatures. To activate the psychoactive effect of THC, this cannabinoid must be heated to $104^{\circ} \mathrm{C}$ - a process called decarboxylation. If this temperature is not reached during distillation, decarboxylation must be carried out in an intermediate step before distillation. In this last process step, pure CBD and THC are finally obtained, which can now be further processed as active ingredients for various applications.

\section{Conclusion}

The methods used to obtain CBD and THC vary, and depend on the type of cannabis and the amount processed. Therefore, the vacuum technology used, the technical parameters of the vacuum pump, such as the ultimate achievable pressure or its pumping speed, must also be individually adapted to the specific processes. A combination of vacuum pumps can also make both economic and technical sense, for example to accelerate processes or to protect heat-sensitive materials from excessive temperatures. It is therefore essential to consult a vacuum specialist when selecting the vacuum supply. A number of companies offer a wide range of vacuum pumps and individual vacuum systems for all applications, together with personal and comprehensive advice. Table 1 gives an indication of the vacuum technologies that can be used.

Table 1. Possible vacuum technologies for use in the various processes. Source @Busch Vacuum Solutions

\begin{tabular}{|c|c|c|c|c|}
\hline \multirow{2}{*}{\multicolumn{2}{|c|}{ Application }} & \multirow{3}{*}{$\begin{array}{l}\text { Vacuum range } \\
0,001-0,5 \text { mbar }\end{array}$} & \multicolumn{2}{|c|}{ Vacuum technology } \\
\hline & & & \multirow{2}{*}{$\begin{array}{l}\text { Laboratory/Small quantities } \\
\text { Scroll } \\
\text { Two-stage rotary vane }\end{array}$} & \multirow{2}{*}{$\begin{array}{l}\text { Industrial production } \\
\text { Screw } \\
\text { Screw with vacuum booster }\end{array}$} \\
\hline DRYING & Freeze drying & & & \\
\hline & $\begin{array}{l}\text { Microwave/ } \\
\text { vacuum drying }\end{array}$ & $10-400$ mbar & $\begin{array}{l}\text { Single-stage rotary vane } \\
\text { Rotary claw }\end{array}$ & $\begin{array}{l}\text { Single-stage rotary vane } \\
\text { Rotary claw }\end{array}$ \\
\hline EXTRACTION & Ethanol extraction & 0,001 - 1 mbar & $\begin{array}{l}\text { Scroll } \\
\text { Two-stage rotary vane }\end{array}$ & $\begin{array}{l}\text { Srew } \\
\text { Screw with vacuum booster }\end{array}$ \\
\hline \multirow[t]{2}{*}{ EVAVORATION } & Rotation evaporator & $50-100$ mbar & $\begin{array}{l}\text { Liquid ring } \\
\text { Single-stage rotary vane }\end{array}$ & $\begin{array}{l}\text { Liquid ring } \\
\text { Single-stage rotary vane }\end{array}$ \\
\hline & Thin film evaporator & 1 mbar & - & $\begin{array}{l}\text { Screw } \\
\text { Screw with vacuum booster }\end{array}$ \\
\hline \multirow[t]{2}{*}{ DISTILLATION } & Short path evaporator & $0,001-1 \mathrm{mbar}$ & $\begin{array}{l}\text { Scroll } \\
\text { Two-stage rotary vane } \\
\text { Two-stage rotary vane with } \\
\text { turbomolecular }\end{array}$ & $\begin{array}{l}\text { Screw } \\
\text { Screw with vacuum booster }\end{array}$ \\
\hline & Thin film evaporator & 1 mbar & $\begin{array}{l}\text { Scroll } \\
\text { Two-stage rotary vane }\end{array}$ & $\begin{array}{l}\text { Screw } \\
\text { Screw with vacuum booster }\end{array}$ \\
\hline
\end{tabular}

